\title{
USERS' PERCEPTIONS ON THE BRIGHTSPACE LEARNING MANAGEMENT SYSTEM
}

\author{
Simone Moseley, Ferrum College, smoseley@ferrum.edu \\ Taiwo Ajani, Ferrum College, tajani@ferrum.edu
}

\begin{abstract}
This study assesses users' perceived usefulness (PU) - and perceived ease of use (PEU) - of the BrightSpace learning management system (LMS) by using data collected through campus mailing lists of a small rural college in the United States. The new LMS which was in the tenth month of usage has become a center piece for how courses, teaching and assignments are experienced by the students. Therefore the LMS is a core domain of interaction between instructors and the students. Although the PEU and PU ratings were observed to be below average, the frequency of the LMS usage suggests that it holds critical information and functionality for the student users.
\end{abstract}

Keywords: Learning Management Systems, BrightSpace, PEU, PU, Technology Acceptance Model, User Experience, User Experience Design

\section{INTRODUCTION}

What are the key descriptors to a successful adoption of learning management system (LMS) by an academic institution? The researchers' familiarity, use and involvement in decision making for the adoption of new LMS suggest that stability, reliability, adaptability and technical support availability are the keys. However, the process of switching and or acquiring new LMS takes enormous resources and investment often involving an eclectic evaluation team of diverse stakeholders from the academic community. Although a thorough process may narrow the risk of failure, it does not guarantee successful adoption or users' acceptance [1,2]. Several authors have expressed concerns about the failure of technology due to users' conception or preconception [1,13], while others stated the need for Information Systems developers to verify requirements by predicting users' acceptance of a new system based on users' evaluations of its specifications [8]. Furthermore, the authors suggested that users should be able to evaluate system specifications during the earliest stages of the system development ideally before building a working prototype. This would be practical if every institution in need of a LMS develops its own system. However, the authors' experience showed that the cost of proprietary technologies are often prohibitive and development time often impractical for most academic institutions who instead would often defer to vendors and manufacturers of over-the-shelf technologies to fulfill institution's LMS needs. The advantages inter alia includes being able to: customize certain features; add certain modules and; integrate third-party applications essential to the adopteeinstitution's peculiar academic operations and needs.

At the beginning of the fall 2014 Semester, the faculty and student body of the College X were introduced to the BrightSpace LMS, developed by the Desire2Learn (D2L) Corporation. This culminated from a year-long assessment, evaluation and comparison of several major LMS in the market. Before the switch was made from Angel LMS, it was determined that: (1) the pricing on the existing system no longer justified its value; (2) the existing system was not in tune with current mobile applications; (3) there was user fatigue regarding how students, faculty and administrators perceived existing system's usefulness; (4) newer systems had better navigational features and functionality; (5) partial integration with the new portal system was possible with a new LMS; (6) newer systems had added values.

Desire2Learn, the parent company of BrightSpace declares that its purpose and vision is to enhance learning through the use of technology [3]. The BrightSpace and its cost implication appeared to fulfil most of the College X's requirements at least from the perspective of the evaluation committee. With about 1450 individuals, the student group is the largest amongst the three main user groups. However, this group was not represented on the LMS committee. Any interaction a user has with a product or service, in this case a LMS, makes up a user's experience (UX). User experience can be defined as anything the user encounters when interacting with a system or technology 
[10]. This can range from how the user interacts visually, mentally, and physically. Furthermore, the user experience honeycomb includes value, usefulness, desirability, accessibility, credibility, findability, and usability [10]. Each of these components play a part in whether or not a user has a good or bad experience. Although several personal discussions with students suggested a better user experience when compared with the previous LMS, it was necessary to evaluate the general perception from the student population.

\section{LITERATURE REVIEW}

Technology is undoubtedly a growing influence in the world. Businesses, such as D2L, have taken notice and taken advantage. LMSs exemplify a paradigm shift in the ways that challenges are addressed through technological solutions. However, the promises of new technologies are unattainable except users accept and adopt innovations [1]. Although user experience may suggest a focus on the user, a good user experience satisfies the goals of both the business and user [14]. Designers and developers must constantly be improving their methods of accomplishing tasks in order to satisfy the never-ending needs of the users. They do this by being in a constant state of anticipating the users' thought processes when engaging with technology [11]. Preparation, design, production, and testing are all processes that need to be carried out when developing websites or software. Research is an important part of this process however, so is a designer's skill in their decision making. It is imperative to make designs that save time for the user.

User experience impacts the success of websites so heavily that even the smallest details must be involved in the design process. Search engines should be considered in the design process. Font and readability of a site can either hurt or enhance a user's experience. The addition of imagery, audio, and video help communicate a business's message to the user. The user may be someone old, young, or middle-aged. Knowing who the audience is can determine if a site is usable or not. For example, what a teenager thinks is easy to navigate may not be as easy for an elderly person. All of these are things to consider when designing a good user experience [6, 9, 15, and 20]. Designers must be decisive about what they chose to include in their designs. These decisions mold the minds of the user for future expectations of a user's experience. Designers must aim to communicate with the user with each decision they chose to implement in their design. Their design choices help communicate with the users. The user's experience can be affected by the choice of colors, the type of fonts, or even the layout of the site.

It is not unusual for students from College $\mathrm{X}$ to voice their concerns about BrightSpace and what it lacks. Such complaints have included: BrightSpace's organization of content does not help the user fulfill their needs upon visiting the site; Its functionalities are not reliable as they do not function properly $100 \%$ of the time; The features of BrightSpace cannot provide a positive user experience when the aspects of UX are not collectively working in favor of the user. Yet others have indicated that BrightSpace is an awesome LMS that has enhanced interaction with faculty. Since perception often determine behavioral intention toward technology, it is important to determine how the general student body perceive the new LMS. Addressing these issues will help developers and researchers in how they approach the development process for future user experience designs (UXD).

College X's student body consists of the "Net Generation" [19]. The Net Generation are also known as The Millennials or Generation Y. The Net generation has a unique experience with technology having not known a world without computers, the World Wide Web, highly interactive video games, and cellular phones. Like the world of technology they grew up in, Net Geners outlook on technology can change rapidly. The College X's new LMS goes beyond learning purposes. Majority of students browse the web of social networking sites, blogs, and wikis on a regular basis [17]. Social networking sites and LMSs share similar qualities in the ways they were made to function; both involve communication and sharing or presenting of data. Faculty and Information Technology staff often consider these similarities and have considered questions relating to the possibility of integrating features that students react well with such as those on social networking site. They have asked if the students would benefit from using other tools on the web [17]. Also they have asked whether or not these are decisions that the users or students should have authority on [17].

Web-based technologies and LMSs, like the ones stated above, are similar based on two main reasons. The first reason is that they are being utilized by the same audience. The second reason is that they are web-based technologies that share similar functions. To reiterate Hoare, web-based technologies such as social networking sites, blogs, and wikis are regularly used by the majority of students. Student must find them useful. Due to lack of 
flexibility, the LMSs cannot integrate its tools to be widely used across the Internet. The installation, customization, and integration to update these systems take a great deal of time [17]. If or when LMSs decide to integrate new features and tools that students find useful, like wikis or blogs, the limits of the system can interfere with that process. Furthermore, a LMS that may function strictly to serve course related objectives stands to hinder users' experience in that it would not be able to mimic the features and tools that users may find useful [17].

The use of LMSs also depends on how it is administered to the student. Faculty and students at College X have voiced their concerns about the LMS in place. Students may find their professor inefficiently utilizing the system. Then faculty may find the students doing the same, while both find it a frustrating experience: the author observed that it is not uncommon to find the learning management features are not well utilized at many colleges and universities [17]. The LMS at College $\mathrm{X}$ allows students to access course related information such as assignments, lectures, grades, quizzes, and tests. Several issues have occurred within the LMS concerning the tools and features that were created to assist the student in their learning experience. For instance, it has been a reoccurrence for content not to be fully operational. Much of the content presented by faculty through LMSs are time sensitive such as projects, homework, tests, and quizzes. When this information is not readily accessible to the user, it creates a constraint on what the student is able to accomplish. Faculty have also voiced their concerns about College X's LMS. In a particular case a faculty member was unable to navigate and utilize the system to allow their students to view missed questions from the quizzes they took. The students were never able to view what questions they got wrong. The organization of content also prevents a positive learning experience. This was exposed when a student found that locating the content they desired proved to be a difficult process. Again, this information was time sensitive, and prevented the student from accessing the content in a timely manner impacting their grade.

When navigating any web-based technology each action the users take should either serve a need or get them one step closer to that need. This ensures a valuable experience on the user's end. Convenience and accessibility will make the users enjoy using the site because their time is being taken into consideration [5]. The LMS system at College $\mathrm{X}$ uses many tabs to access content within a course section. The user must make several clicks to get to the desired content. Navigation is a critical aspect of providing a good user experience. The user should have the ability to locate the information they need in an efficient amount of time with little to no effort. Content that is presented to the user, whether information or aids in navigation, should be brief and specific to the user's needs. On websites this can affect the bounce rate (the percentage of viewers who, upon visiting a website, leave without viewing any additional pages before an analytics based timeout occurs) when not developed effectively [9]. When faculty opts to integrate a LMS into their course, the students do not have the option of leaving the system if found to be a frustrating experience. Each student needs to gain access to the system in order to obtain the content presented within as the course requires. Research shows that usefulness is strongly linked to usage [7]. Features that do not efficiently and effectively serve a purpose put the usefulness of that system in question.

LMSs are useful in the sense that they have enhanced the learning experience from when it was just about pen and paper. However, it must be noted how it has brought its enhancements, and that is through technology. When assessing technology, it's about whether or not the system serves a useful purpose to the user efficiently and effectively. The LMS at College X lacks a sense of usefulness compared with the features and functionality of other web-based technologies students find useful. Therefore, it is believed that students will, "consequently find LMSs and the tools within them inferior to those they are already using freely on the Internet" [17]. The author also opined that the sense of inferiority may come from the look, the feel, or the amount of functionality offered [17]. Usefulness is found in the looks, feel, and functionality of that web based technology. It is an important component because it can determine the success of a technology.

When developing any product or service (in this case, LMS) the designer must balance focus between creating functional features and creating an interface the user will find appealing [4]. Providing a good user experience in turn provides the user with a useful product or service. In the process of developing a good user experience it is important to keep in mind the needs of the users. Developers can make sure of this by constantly thinking about what the users' habits, expectations, and thought processes may be. Those who develop successful user experiences are those who put themselves in the shoes of their users [11].

Developing a good user experience can eliminate having a frustrating experience with technology. Providing a good user experience is heavily detail-oriented. The focus revolves around usability which can be defined as, "the ability 
of the average person to operate a function based off of pure instinct [12]." The presence of usability results in an uncomplicated experience that does not frustrate the user. If the user is able to operate a function without becoming frustrated, then usability is present. As a web based technology, LMSs have the responsibility of being obvious and instinctual to the user [12].

Most users are extremely conscious of how long it takes to get the information they need. This makes it imperative that the features designed save time for the user. One important feature is the search box [12]. Developers must avoid the common mistakes linked with implementing a search box. When search engines are too literal, usability decreases. Literal search engines are unable to comprehend typos, plurals, hyphens, and other types of punctuation [15]. The LMS at College X does not have a search engine. An obstacle that LMSs face has become the constant evolvement to match the user's expectation in order to prove useful. The rapid pace at which technology develops has shaped the minds of the Net Generation. Subsequently, their expectations of technology can evolve at a rapid pace, creating an obstacle for LMSs. However, the Net Generation do not solely rely on technology in the classroom for a positive learning experience. A study showed that eight out of ten students ranked the "professor's experience and expertise" to be most important. "Professor's ability to customize the class using the current technology [LMSs] available" and, "Professor's ability to professionally convey lecture points using contemporary software [PowerPoint]" were separated by less than half a point as the second and third most important item [16].

The Net Gen's expectations are for faculty to utilize LMSs, a platform for contemporary software (such as PowerPoint), in a way that effectively communicates their knowledge and expertise. Another poll that was taken by a different set of students voted on what they believed to be a balanced learning environment. A fifty percent lecturing and fifty percent interactive learning environment had the highest rating by a land slide [16]. This study involved several interviews to gain a deeper insight of the Net Gen's expectations. The use of PowerPoint in the classroom was a reoccurring theme among students. Therefore, it was concluded that the Net Generation still holds relatively modest expectations for what constitutes leading-edge technology in the learning space [16]. Students from the Net Gen view technology such as LMSs to be everyday tools made to assist them. To Net Geners, the definition of technology is pivoted on customization. Technology is perceived as a tool that adapts to Net Geners' needs, and not something that requires them to adapt [16]. This provides some insight considering how PowerPoint is used by students today. The purpose of LMSs have been shifted to being used as storage facilities for lecture notes and PowerPoint presentations which tend to promote a culture of dependency rather than autonomy [17].

The behavioral intention of users of a newly introduced technology has been anchored on the amount of users' involvement during development $[8,13]$. Davis' research suggests the perceived usefulness and perceived ease of use are the two most important variables in the Technology Acceptance Model [7]. The Task-Technology Fit model has been used in conjunction with the TAM in similar studies [18], perhaps because of its ability to accommodate the PEU and PU constructs that are associated with the latter. However, TAM was adopted for this study due to resource and time constraints. It is expected that future expanded studies could include other models that are pertinent to technology adoption and user behavioral intentions. The students and faculty of College $\mathrm{X}$ arrived on campus in the fall of 2014 to learn the intricacies of a new LMS - which was radically different from what they were previously accustomed to. The transition from one system to another can change a user's outlook on how well the system actually functions. Bowen and Young observed that performance gains can be obstructed by users' unwillingness to accept and use another system [7]. The user may expect the system to operate similarly to previous experiences with technology. Therefore, when new technology is presented and does not operate similarly, the user may have a negative outlook on the usefulness of that technology. However, change is inevitable, but when it does occur there are methods available to assure that those involved can transition with ease. Education is essential in this regard [2]. In the process, it may be found out that the change was for the better. Developing a perceived usefulness and perceived ease of use scale can help better determine system use [7]. All parties can benefit from using the two scales when implementing a new technology. Measuring the perceived usefulness and perceived ease of College X's LMS would benefit the school, the vendors, and the information systems managers. If the LMSs' use were assessed prior to being invoked, College $\mathrm{X}$ would know if the system holds value to its users and institution. Measuring the two scale items assesses user demand for new design ideas, which benefits the vendors. Lastly, information systems managers get to evaluate the offers made by the vendors [7]. Many variables influence system use; however previous research suggests that perceived usefulness and perceived ease of use are especially important [7]. 


\section{RESEARCH METHODOLOGY}

Our research centered upon the following research questions: (1) What is the perceived usefulness (PU) of Brightspace? (2) What is the perceived ease of use of Brightspace?

To answer the research questions, a quantitative study was conducted. This study adapted TAM-based scales for measuring PU and PEU as well as system usage [7].

\section{Study Design}

The study received its data from a survey that was made using Google Forms. The results presented by Google Forms were then inputted into an Excel spreadsheet programmed to calculate the average PU and PEU ratings. The survey comprised of thirty questions. Four demographic questions were asked including if the participant were eighteen years or older, their age, their major, and their current class status. A total of fourteen (14) questions were asked to determine the perceived usefulness of BrightSpace, while eleven (11) questions were asked to determine the perceived ease of use of BrightSpace. PU and PEU were measured with a series of questions that utilized a Likert scale which can also be considered as a rating scale. The Likert scale's measures consisted of a rating from one to five (1-5): $1=$ not at all; $2=$ somewhat true; $3=$ neutral; $4=$ true; $5=$ very true

\section{Target Population}

The target population is the student body of a four-year small rural College located in Central Virginia. About 1450 students are registered with estimated male to female ratio of 60:40. However, since race was not a variable factor in the study, the authors found it redundant to be included in this study. At least ninety (90) percent of the student body live on campus. The College is diversified and includes ethnic students from several national and international geographic zones. Eligibility requirement for participation included registration as a student, as well as a minimum 18 years reported age. The College provides 33 areas of Major studies and is made up of three schools namely: the School of Arts and Humanities; the School of Natural Sciences and; the School of Social Sciences and Preprofessional Studies. Each of these Schools is administered by a School Dean. The survey had a total of sixty-four respondents having excluded students under 18 years. Therefore the respondents are regarded as belonging to the Net generation [19].

\section{Procedure}

An email containing the link to the survey was sent twice between April 13 and 20, 2015. The survey was disseminated via the campus wide email which populates every student's inbox. Response were subsequently provided through self-selection since the survey was designed to be voluntarily taken. The respondents were asked the same questions in the same order. First, four demographic questions. Second, fourteen Likert scale questions determining PU. Third, eleven Likert scale questions determining PEU. Lastly, the respondents were asked how often they use Brightspace.

\section{Data Analyses}

The responses from both the perceived usefulness (PU) and perceived ease of use (PEU) scales were calculated using the following formulas:

$$
\begin{gathered}
\frac{\sum\left(\frac{\left(R s_{1}+R s_{2}+R s_{3} \ldots R s_{14}\right) 1 s t}{n}\right)+\cdots+\left(\frac{\left(R s_{1}+R s_{2}+R s_{3} \ldots R s_{14}\right) n t h}{n}\right)}{N} \\
\begin{array}{l}
\text { Rs }=\text { respondent's score on scale question } \\
1^{\text {st }}=\text { the first person's average score for the scale }
\end{array}
\end{gathered}
$$


nth $=$ the sixty-fourth person's average score for the scale

$\mathrm{n}=$ total number of scale questions

$\mathrm{N}=$ total number of respondents

Each respondent's rating was added together. The total was then divided by the total number of questions that scale comprised of. This part of the equation obtained the average score for each respondent. After individual averages were calculated, each respondent's rating was then added together and divided by the total number of respondents in order to determine what the perceived ease of use and perceived usefulness were.

\section{RESULTS AND DISCUSSION}

Most of the respondents have never lived in a world without computers. The minds of the Net Generation have been shaped by the world of technology they have lived in. The Net Gen views technology as a tool to assist their needs therefore, when a technology does not agree with their likeness that can result in a rating of usefulness undergoing more scrutiny than ease of use (Roberts, 2004). Prior to this study being conducted students at College X spoke of instances when the features of BrightSpace had not been readily accessible or fully operational. A majority of the respondents reported that BrightSpace did not save them time with College work thus it takes more time to accomplish task. The LMSs' lack of accessibility that the students at College X expressed may be a direct result of these findings.

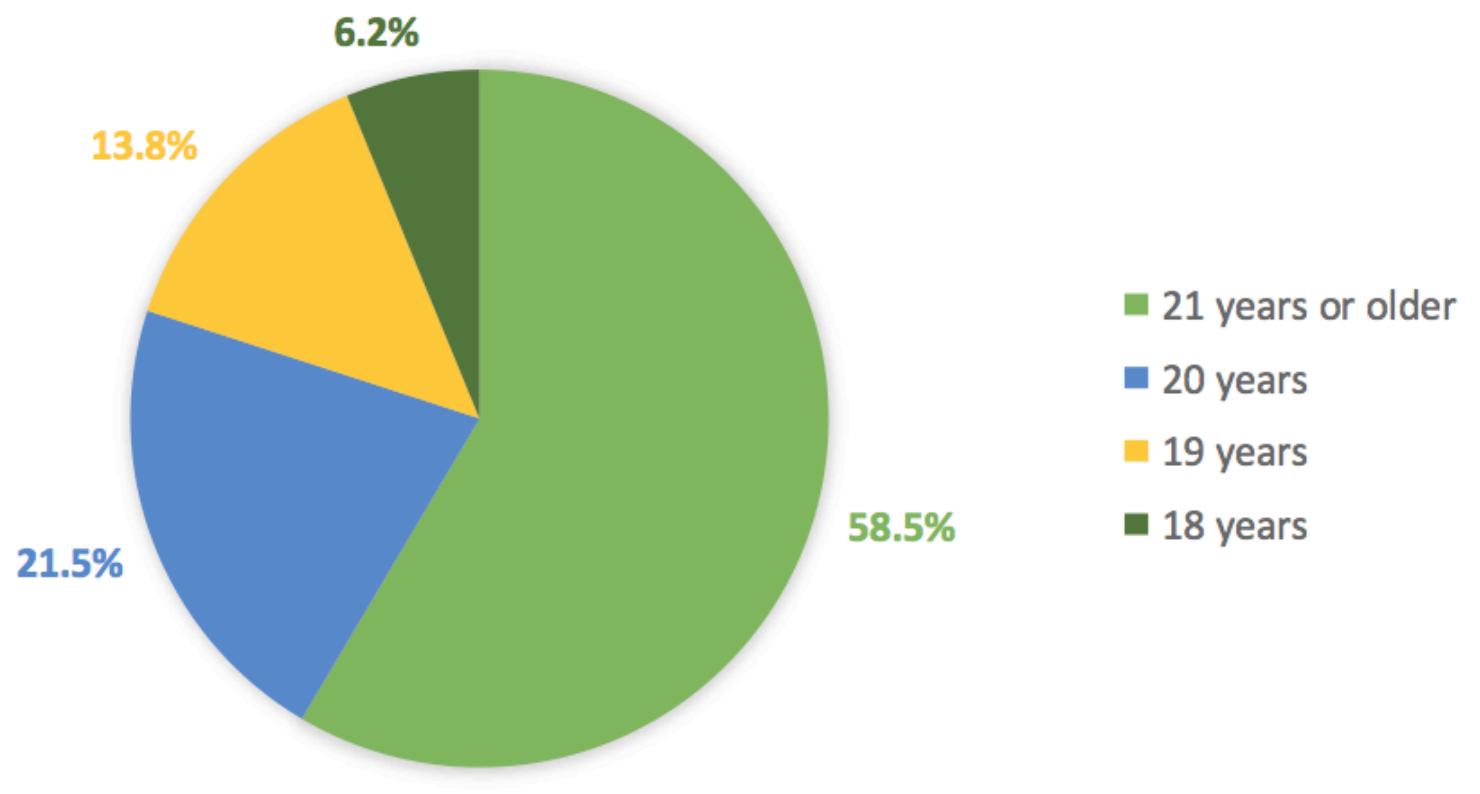

Figure 1. Age of Respondents

When asked whether or not Brightspace enhanced effectiveness while doing school work the majority reported that BrightSpace did not. The Net Gen can be considered the most technologically savvy generation thus far. That is to say this generation can find somewhat ease in using a system that does not necessarily exude a high ease of use. For instance, when asked to indicate to which degree confusion may be experienced when utilizing BrightSpace, the majority reported that they did not become confused when using the system. Furthermore, when asked whether or not mistakes were frequently made while using BrightSpace, the majority reported that mistakes were rarely made when using the system. The LMSs' below average ratings of PU and PEU may continue to be a result of the user's prior experience with other technologies. For instance, BrightSpace was adopted in the fall semester of 2014. College X utilized a different LMS the previous year. The user's experience with the college's former LMS creates the probability of the user projecting the knowledge obtained on how a LMS should function onto a new system 
such as BrightSpace.. The respondent's rating may be influenced by previous encounters with similar technologies. Bowen and Young suggested that users can be reluctant to change in technologies ultimately affecting the outlook of what is perceived as a useful technology with ease of use [7].

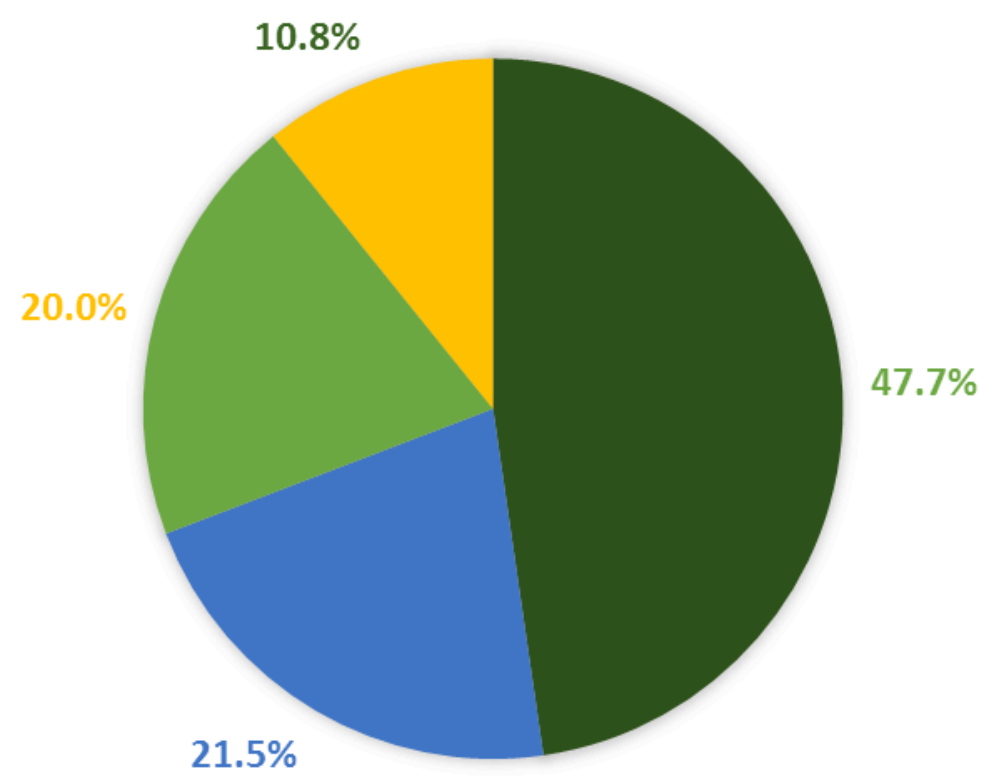

Senior

- Junior

- Freshman

Sophomore

Figure 2. Respondents' Academic Status 


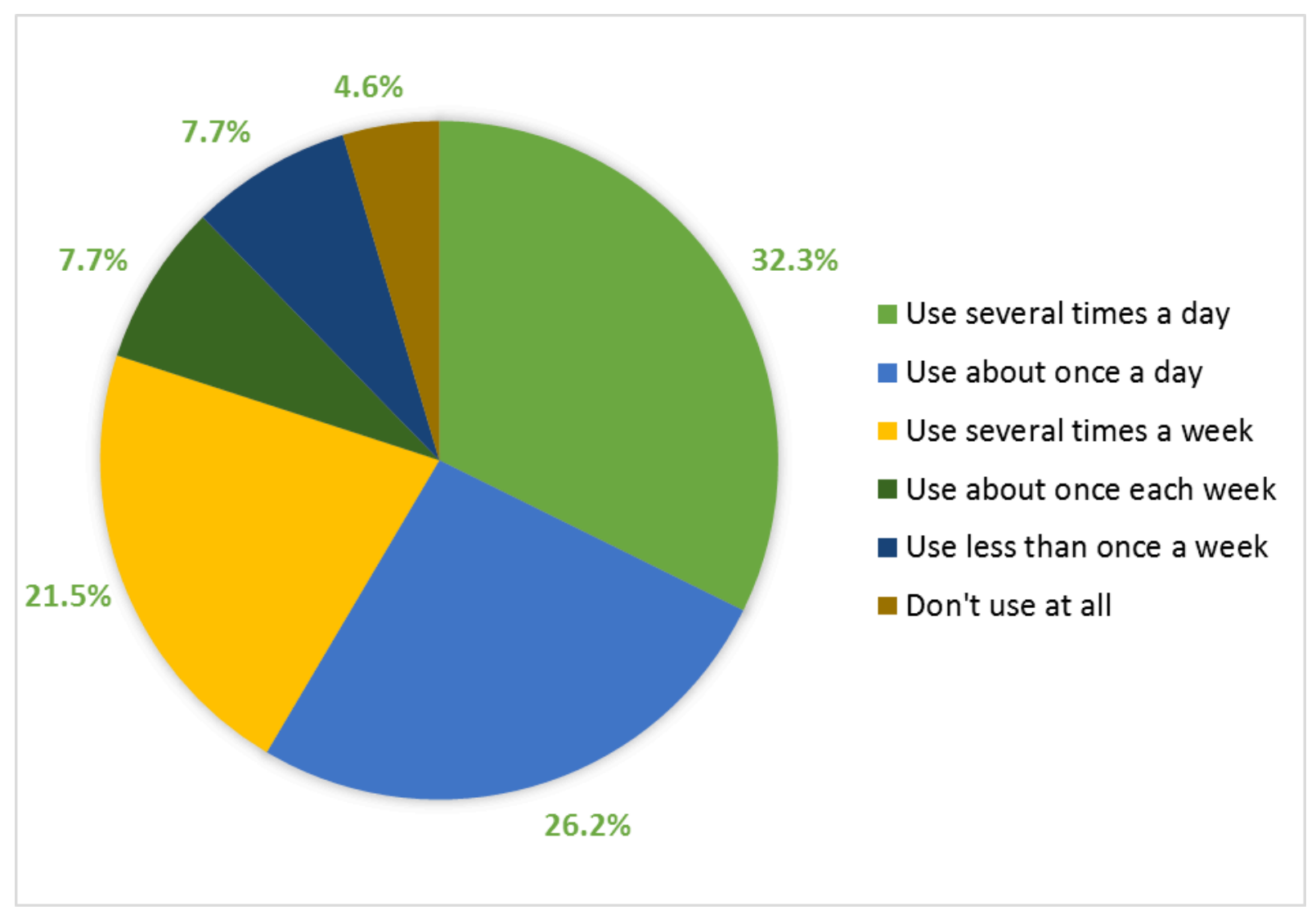

Figure 3. Users' Reported Frequency of BrightSpace Usage

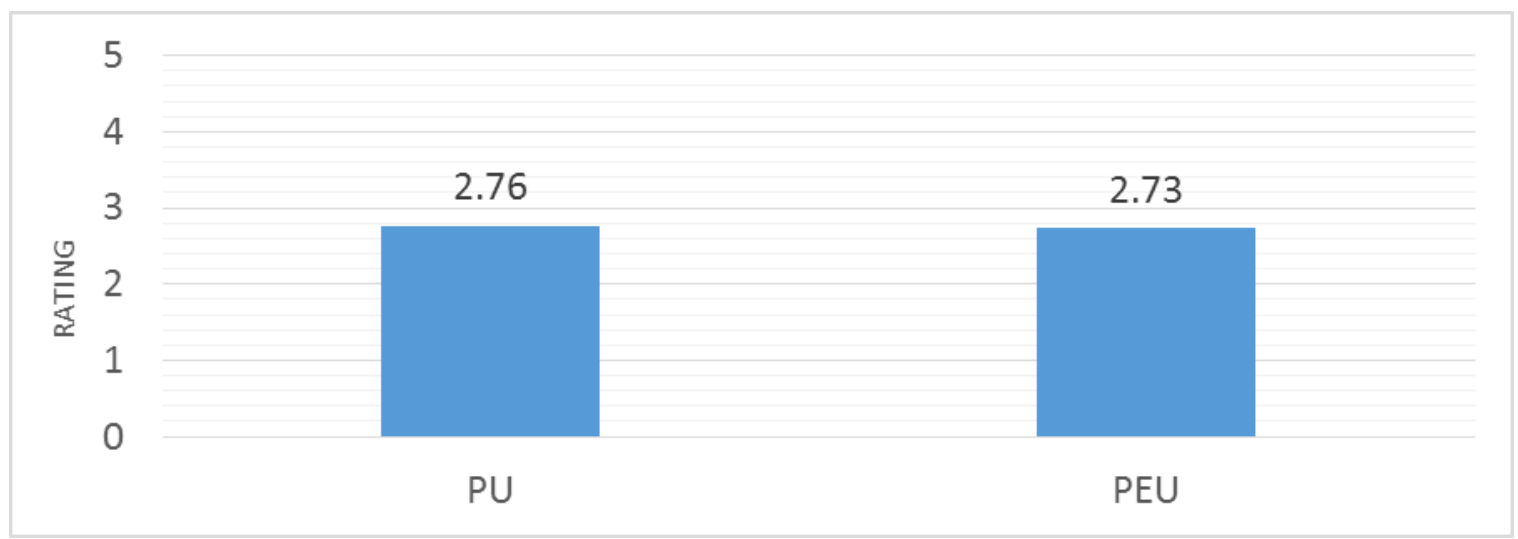

Figure 4. Overall Perceived Usefulness and Perceived Ease of Use Rating

Despite the reasoning behind the results of the survey, PU and PEU received below average ratings. Although PU and PEU were below average, students are still using the system frequently. The majority reported usage of about once a day or several times a day. Research conducted suggests that PU and PEU are the two most important variables when forecasting the use of a system [7]. Looking at the results a high system usage should not be anticipated with low PU and PEU ratings. However, BrightSpace holds important content that may be required for the course or courses being taken. That is to say the users of BrightSpace are tolerating the system's low PU and PEU in order to access information that may be needed. It was suggested that users are more likely to use unfavorable systems when that system administers critically needed information [7]. 


\section{CONCLUSIONS}

There is value in knowing system use for example, Robey states, "A system that does not help people perform their jobs is not likely to be received favorably" [7]. There are many factors that can determine the usefulness of a technology. One is knowing your audience and ensuring developers take into account their needs. Another is understanding the purpose of the system in use so that it may be utilized efficiently and effectively. Finally, one must heavily consider how perceived usefulness and perceived ease of use impact system use. Whether or not College X's LMS is useful, there will always be the opportunity of improving performance.

Educational institutions that are in contemplation of acquiring new technologies should utilize the Technology Acceptance Model to better determine whether or not that technology will fulfill the needs of its users. When acquiring a new technology it needs to be known that the purpose of that technology will satisfy the user. Otherwise the institution increases the risk of obtaining technologies the user will not find useful. A recommendation for College $\mathrm{X}$ would be to randomly select a group of students to test new technologies the institution wishes to acquire. After testing, it would be recommended to have those same students answer the questions provided by the PU and PEU scales. This way it can be better assessed to which degree the users will find a technology useful

Based upon the results of our study, we concluded that significant differences existed between male and female computer information systems students in their ethical beliefs. Though as noted previously, there was a small sample population of female students. This is significant because it supports the industry study gender differences that show that software piracy and hacking tend to be more prevalent amongst males than females.

\section{REFERENCES}

1. Ajani, T. (2014). Exploring the Implications of Technology Acceptance Models for Sensor-based Global Health Technologies. 2014. 2014 Proceedings of the Information Systems Educators Conference. ISSN: 2167-1435, Baltimore, Maryland USA

2. Ajani, T. (2014). Decision Support Systems: An Exploratory Research Examining Public Health Educators' Perception of Global Sensor Systems. Issues in Information Systems journal, Volume 15, Issue II, pp. 31-38, 2014.

3. Baker, J. (2014, July 14). BrightSpace - The Next Era of Innovation for D2L | BrightSpace. BrightSpace by D2L. D2L Corporation. Retrieved from http://www.brightspace.com/blog/brightspace-next-era-innovationd21/\#.VNU7AvnF-pr

4. Brewer, J. (2010, February 05). UTILITY VS. BEAUTY. 52 Weeks of UX. A Josh \& Josh Production. Retrieved from http\%3A\%2F\%2F52weeksofux.com\%2Ftagged\%2Fweek_5

5. Cornett, C. (2014, June 21). Methods to Achieve User Delight. InspireUX. Retrieved from http $\% 3 \mathrm{~A} \% 2 \mathrm{~F} \% 2 \mathrm{Fwww}$.inspireux.com\%2F 2014\%2F06\%2F21\%2Fmethods-to-achieve-user-delight $\% 2 \mathrm{~F}$

6. Cousins, Carrie. (2013) "The Importance of Designing for Readability." Design Shack. Compact Creative, 22 July 2013. Web. 01 Feb. 2015.

7. Davis, F. D. (1989). Perceived Usefulness, Perceived Ease of Use, and User Acceptance of Information Technology. MIS Quarterly. Retrieved from http://iris.nyit.edu/ kkhoo/Spring2008/Topics/TAM/PercieveUsefulness_MIS.pdf

8. Davis, F. D. \& Venkatesh, V. (2004). Toward preprototype user acceptance testing of new information systems for software project management. Engineering Management, IEEE Transactions, 51(1), 31-46.

9. Frehtenbaum, P. (2013). The Usability Of Your Website Starts With Its Content. Usability Geek. Retrieved from http://usabilitygeek.com/usability-website-starts-content/

10. Guo, F. (2012). More Thank Usability: The Four Elements of User Experience, Part I: UXmatters. Retrieved from http://www.uxmatters.com/mt/archives/2012/04/more-than-usability-the-four-elements-of-userexperience-part-i.php\#sthash.q5Hg3HiT.dpuf

11. Harvey, A. (2013) “User Experience: What Is It And Why Should I Care?” Usability Geek. Usability Geek, 02 July 2013. Retrieved 31 Jan. 2015 from: http://usabilitygeek.com.user-experience/

12. Horrocks, R. (2009). 10 Usability Lessons from Steve Krug's Don't Make Me Think. UX Booth RSS. UX Booth. Retrieved from http://www.uxbooth.com/articles/10-usability-lessons-from-steve-krugs-dont-make-methink

13. Jain, A. (2006). When preconceptions matters: Understanding preprototype usefulness of information 
technology, the case of a municipal wireless network. Ph.D. Dissertation, Temple University, 2006, 170 pages; AAT 3247270

14. Kuniavsky, M. (2007). User experience and HCI. USER EXPERIENCE AND HCI. http://www. orangecone. com/hci_UX_chapter_0.7a.pdf

15. Nielsen, J. (2011). Top 10 Mistakes in Web Design. NNGroup. Nielsen Norman Group. Retrieved from http://www.nngroup.com/articles/top-10-mistakes-web-design

16. Roberts, G. R. (2004). TECHNOLOGY AND LEARNING EXPECTATIONS OF THE NET GENERATION. EDUCAUSE. Retrieved from http\%3A\%2F\%2Fwww.educause.edu\%2Fresearch-and-

publications $\% 2 \mathrm{Fbooks} \% 2 \mathrm{Feducating}$-net-generation\%2Ftechnology-and-learning-expectations-net-generation

17. Sclater, N. (2008). Web 2.0, Perosnal Learning Environments, and the Future of Learning Management Systems (Research Bulletin, Issue 13). Boulder, CO: EDUCAUSE Center for Applied Research. Retrieved from http://www.educause.edu/ecar

18. Usoro, A. (2010). Task-Technology Fit and Technology Acceptance Models Applicability to e-Tourism. Journal of Economic Development, Management, IT, Finance and Marketing, 2(1), 1-32, March 2010.

19. Waterworth, N. (2013). Generation X, Generation Y, Generation Z, and the Baby Boomers. RSS 092. Talented Heads. Retrieved from http://www.talentedheads.com/2013/04/09/generation-confused

20. Weinschenk, Susan (2013). "The Five Worst UX Mistakes Websites Make." UX Mag. UX Magazine, 06 Mar. 2013. Web. 31 Jan. 2015. http://uxmag.com/articles/the-five-worst-ux-mistakes-websites-make 